\title{
Balkanologie
}

Balkanologie Revue d'études pluridisciplinaires

Vol. III, n 1 | 1999

Volume III Numéro 1

\section{Rajčevski (Stojan), Bălgarite mohamedani (Les Bulgares musulmans)}

Sofia : éditions universitaires Sv. Kliment Ohridski, 1998, 223 p. (résumé anglais, 24 p. d'illustrations médiocres, pas de cartes, mais de nombreux tableaux statistiques)

Bernard Lory

\section{OpenEdition}

1 Journals

Édition électronique

URL : http://journals.openedition.org/balkanologie/301

DOI : 10.4000/balkanologie.301

ISSN : 1965-0582

Éditeur

Association française d'études sur les Balkans (Afebalk)

Édition imprimée

Date de publication : 1 juillet 1999

ISSN : 1279-7952

Référence électronique

Bernard Lory, «Rajčevski (Stojan), Bălgarite mohamedani (Les Bulgares musulmans) », Balkanologie [En ligne], Vol. III, n 1 | 1999, mis en ligne le 03 juin 2008, consulté le 17 décembre 2020. URL : http:// journals.openedition.org/balkanologie/301 ; DOI : https://doi.org/10.4000/balkanologie.301

Ce document a été généré automatiquement le 17 décembre 2020.

(c) Tous droits réservés 


\section{Rajčevski (Stojan), Bălgarite mohamedani (Les Bulgares musulmans)}

Sofia : éditions universitaires Sv. Kliment Ohridski, 1998, 223 p. (résumé anglais, 24 p. d'illustrations médiocres, pas de cartes, mais de nombreux tableaux statistiques)

\section{Bernard Lory}

\section{RÉFÉRENCE}

Rajčevski (Stojan), Bălgarite mohamedani (Les Bulgares musulmans), Sofia : éditions universitaires Sv. Kliment Ohridski, 1998, 223 p. (résumé anglais, 24 p. d'illustrations médiocres, pas de cartes, mais de nombreux tableaux statistiques)

1 Les Pomaks (Bulgares musulmans) ont fait l'objet de nombreuses publications en Bulgarie comme dans les autres pays balkaniques au cours des dix dernières années. Ceci ne signifie pas que la connaissance scientifique sur cette communauté progresse véritablement. L'ouvrage présenté ici est un exemple de la manière de faire du neuf avec du vieux.

2 Il se compose de trois parties, inégales en volume, et sans lien les unes avec les autres. La première (pp. 11-94) est un survol des sources historiques concernant les Pomaks pour la période 1830-1878. Ces sources se composent de témoignages des voyageurs occidentaux, pour la plupart déjà accessibles au lecteur bulgare en traduction, et d'autre part des écrits des militants du réveil national bulgare parus en général dans la presse de l'époque. Toutes ces sources sont connues et répertoriées, elles ont servi à alimenter les études sur les Pomaks depuis les années 1920-1930 jusqu'à nos jours. Plus grave : l'information fournie par ces sources n'est jamais mise en question. Or même les voyageurs les plus sérieux et les plus érudits peuvent commettre des erreurs (sans parler des "touristes" qui glanent l'information dans les auberges de grand chemin); 
quant aux militants nationaux, ils sont prêts à tous les excès pour le bien de la cause. L'auteur cible bien sûr la célèbre mystification littéraire Veda Slovena, mais soutient que les deux volumes incriminés contiennent néanmoins une information précieuse (p. 39). Qui retirera alors les fruits pourris du panier? Il tient pour authentique la chronique du pope Metodi Draginov (p. 112) qu'un grand nombre d'historiens bulgares tient pour apocryphe. Il ne met nullement en cause la qualité de l'information fournie par d'ardents patriotes tels que G. Rakovski ou L. Karavelov. Et surtout, il cesse sa présentation des sources précisément au moment où une information à peu près fiable commence à être disponible, c'est-à-dire à partir de 1878, ce qui, méthodologiquement, est tout à fait incompréhensible.

3 La deuxième partie (pp. 95-187) est un survol géographique des différentes zones peuplées de Pomaks (Bulgarie du nord [Pomak de Loveč], Rhodopes [c'est-à-dire Rhodopes bulgares], Macédoine, Thrace occidentale [c'est-à-dire Rhodopes grecs], Albanie, Asie mineure, Thrace orientale, région orientale de la Stara Planina bulgare).

4 On ne comprend pas pourquoi, dans une vision aussi large des "Bulgares musulmans", les Goranis du Kosovo n'ont pas été inclus. Cette présentation par zones reste, elle aussi, très historique. La plupart des sources statistiques citées date de la fin du XIX ${ }^{\text {ème }}$ siècle, à l'extrême limite, on atteint la Deuxième Guerre mondiale, sauf - comme c'est étrange ! - concernant la Macédoine, la Grèce et l'Albanie.

5 La troisième partie (pp. 188-203) traite des différents noms collectifs servant à désigner les Bulgares musulmans.

6 Ce qui frappe dans cet ouvrage, c'est qu'il est entièrement tourné vers le passé. Quoique laborieux et brassant une quantité d'informations importante, il ne fait pas avancer la question. À vrai dire, il ne pose aucune question, il ne soulève pas de problème. C'est un ouvrage assertif, qui brasse une information connue à $90 \%$, et se contente de répéter que les Bulgares musulmans sont des Bulgares. Le chercheur reste donc déçu. Je ne pense pas que les Pomaks eux-mêmes puissent retirer de cette compilation quoique ce soit qui les aide à mmieux définir leur place en Bulgarie et dans les Balkans. Reste le public des Bulgares non-musulmans qui a besoin d'être sans cesse rassuré sur cet Autre qui est censé être un Identique. Il est pour le moins naïf de croire que les incantations nationales datant du Văzraždane romantique puissent avoir la moindre efficacité à la fin du XX ${ }^{\text {ème }}$ siècle, après la guerre en Bosnie. Il est impératif d'élaborer de nouvelles grilles de lecture pour déchiffrer la réalité d'aujourd'hui. 